\title{
The resilient frugivorous fauna of an urban forest fragment and its potential role in vegetation enrichment
}

\author{
Eduardo Delgado Britez Rigacci ${ }^{1}$ (D) Natalia Dantas Paes $^{1}$ (D) $\cdot$ Gabriel Moreira Félix ${ }^{1}$ (D) $\cdot$ Wesley Rodrigues Silva $^{2}$ (D)
}

Accepted: 23 November 2020 / Published online: 6 January 2021

(C) Springer Science+Business Media, LLC, part of Springer Nature 2021

\begin{abstract}
Anthropocentric defaunation affects critical ecological processes, such as seed dispersal, putting ecosystems and biomes at risk, and leading to habitat impoverishment. Diverse restoration techniques could reverse the process of habitat impoverishment. However, in most of the restoration efforts, only vegetation cover is targeted. Fauna and flora are treated as isolated components, neglecting a key component of ecosystems' functioning, the ecological interactions. We tested whether the resilient frugivorous generalist fauna can improve habitat quality by dispersing native plant species through the use of fruit feeders as in a semideciduous seasonal urban forest fragment. A total of 32 sampling points was selected at a heavily degraded 251-ha urban forest fragment, with feeders installed at two heights monitored by camera-traps. Variable quantities of native fruits of 27 zoochorous species were offered alternately in the feeders. Based on more than 36,000 h of video records, Turdus leucomelas (Class Aves), Sapajus nigritus (Class Mammalia), and Salvator merianae (Class Reptilia) were recorded ingesting the highest fruit species richness. Didelphis albiventris (Class Mammalia) was the most frequent visitor but consumed only pulp in most of the visits. The frugivorous birds were recorded at a high visitation rate and consumed a wider variety of fruits. Our study opens a new avenue to combine the traditional approach of ecosystems recovery and ecological interactions restauration in an urban forest fragment.
\end{abstract}

Keywords Animal-feeders $\cdot$ Defaunation $\cdot$ Fragmentation $\cdot$ Frugivory $\cdot$ Urban ecology and tropical forest

\section{Introduction}

A rapid expansion of anthropic activities such as agriculture, urban, and industrial boundaries has accelerated natural areas' degradation, reducing them to fragmented communities (Tabarelli and Gascon 2005). This process causes loss of diversity, richness, and biomass of the fauna in a process called 'anthropocentric defaunation' (Redford 1992; Dirzo et al. 2014). Since most of the Neotropical vertebrate fauna are frugivorous (Kissling et al. 2009) and $80 \%$ of Neotropical woody plants produce vertebrate-dispersal seeds (Malhi et al. 2014), defaunation has the high potential to affect

Eduardo Delgado Britez Rigacci eduardorigacci@gmail.com

1 Programa de Pós-graduação em Ecologia, Departamento de Biologia Animal, Instituto de Biologia, Universidade Estadual de Campinas, Campinas, SP, Brazil

2 Departamento de Biologia Animal, Instituto de Biologia, Universidade Estadual de Campinas, Campinas, SP, Brazil essential ecosystem functions - jeopardizing key mutual relationships such as animal-mediated seed dispersal (Gardner et al. 2019).

In many systems, the absence of frugivores alters the floristic composition, benefiting plant species with abiotic dispersion (Wright and Duber 2001). This reduction of zoochoric plants generates negative feedback between frugivores and plant communities. Forests with fewer zoochoric plants offer fewer resources to vertebrates (Terborgh et al. 2008), affecting their survival, growth, and reproduction, contributing to fragments' defaunation. The diminishing vertebrate's biomass affects the quantity and quality of seed dispersal (e.g., empty forest process by Redford 1992) (Ness et al. 2016) and the soil's fertilization through urine and feces (Feeley and Terborgh 2005). Less fertilization reverberates back into plant communities, decreasing rates of the establishment of new adults. Thus, the alteration in seed dispersal patterns influences the ecosystem's capacity to maintain plants and animal populations in the medium and long term, especially in the tropics (McConkey and Brockelman 2011; Terborgh 2013).

However, in some areas, the residual faunal species may persist due to their wide niche width and provide functional 
replacement of some already absent species' ecological functions, promoting the reversal of floristic impoverishment through seed dispersal (Jordano et al. 2007; Emer et al. 2018; Bogoni et al. 2020). The reversal of habitat impoverishment is imperative in depleted biodiversity tropical hotspots, such as the Brazilian Atlantic Forest, which have only small areas remaining. Some of them are compressed into urban forest fragments (Ribeiro et al. 2009). The loss of biodiversity in such urban forests fragment can disrupt medium and longterm services rendered by flora and fauna which are essential to surrounding anthropic communities (Estevo et al. 2017; Wintle et al. 2019), such as water supply, climate regulation, and cultural services (Kremer et al. 2016). The drastic diminution of green patches can also promote the emergence of animal-borne infectious diseases (e.g., the recent world-wide coronavirus pandemic) (Lam et al. 2020; Zhou et al. 2020). Currently, $55 \%$ of the world population lives in cities (Fent 2008), and by 2030 the percentage will reach about $70 \%$ (Seto et al. 2012; United Nations 2018). Urban forests will be even more ubiquitous in our changing landscapes. Hence, finding ways to promote habitat enrichment and ecological restoration are necessary moves to mitigate the human impact on urban landscapes (Enssle and Kabisch 2020).

In many tropical research projects, active ecosystem restoration, i.e., the process of land management by planting vegetation, weeding, burning, and thinning (Benayas et al. 2008), is the most common method to promote habitat enrichment (Brancalion et al. 2019), a technique based solely on plant taxonomic richness or on a single ecosystem function (Jones et al. 2018).Furthermore, active restoration could present some drawbacks related to high-cost (Birch et al. 2010), low- effectiveness (Crouzeilles et al. 2017), less carbon storage (Lewis et al. 2019), and overlooking the frugivore role in this process (e.g., with a wide choice of faster growth nonzoochorous native plant (Brancalion et al. 2018)). In doing so, the ecological interactions, an essential component of biodiversity, is neglected (Valiente-Banuet et al. 2015; McAlpine et al. 2016). Employing fauna on ecological restoration projects could rebuild interactions among species. These interactions promote vital ecosystem function, for instance, seed dispersal by frugivores (Cristescu et al. 2013; Catterall 2018). Studies that directly link fauna and flora in floristic enrichment are urgently needed to promote a sustained ecosystem recovery (Ribeiro da Silva et al. 2015; Hale and Swearer 2017; Moreno-Mateos et al. 2020).

Thus, we employed an alternative approach, using the potential generalist species, very resilient to habitat disturbance, in a degraded urban fragment to promote flora enrichment through fruit feeders as a tool. Feeders are widespread in the temperate zone for recreational and conservation reasons (Ewen et al. 2015) and may provide supplementary resources to generalist fauna, mainly during winter, a period with a shortage of fruits in many ecosystems (Robb et al. 2008;
Møller et al. 2015). We assessed the residual fauna's relative importance as frugivores in an urban Brazilian Atlantic forest fragment by conducting a manipulation experiment. By providing an enriched supply of zoochorous plants within feeding stations, we aimed to characterize the composition, the spaceuse, and temporal variation in the fruit consumption of these potential seed dispersers, identify fruit traits that enhance the attractiveness of artificial fruit feeders, and, ultimately, verify whether fruit feeders set in forest fragments are appealing for resilient frugivores. We hypothesize that frugivorous generalist fauna has a strong potential to promote functional replacement in the seed dispersal process and habitat enrichment.

\section{Material and methods}

\section{Study area}

The study was conducted in a heavily degraded 251-ha forest fragment (23 K 283404.00 E, 7474649.00 S), hereafter called Santa Genebra (SG), a remnant of the Seasonal Semideciduous Forest, one of the physiognomies of the Atlantic Forest Domain (Oliveira-Filho and Fontes 2000). SG is a federal reserve with 252 ha located at Campinas municipality, São Paulo State, surrounded by a mosaic of agricultural and urban areas (Morellato and de Freitas Leitão Filho 1995). Two main successional stages could be found in the fragment: early and late (Guaratini et al. 2008). The regional climate according to Köeppen classification is CWA, characterized by a hot and humid season between October and March, with the mean temperature ranging between 22 and $24{ }^{\circ} \mathrm{C}$ and with rainfall averages of $1057 \mathrm{~mm}$, and a dry season, from April to September, with the mean temperature of between 18 and $22{ }^{\circ} \mathrm{C}$, with rainfall averages of $35 \mathrm{~mm}$ (CEPAGRI 2019).

The vertebrate frugivorous fauna of SG has been studied over the last 40 years. Even without any changes in the total fragment area over time, SG has lost most of the large-sized bird and mammal frugivores (Aleixo and Vielliard 1995; Willis and Oniki 2002).

\section{Sampling}

From September 2017 to September 2018, we kept 32 artificial feeding stations at SG, separated at least $200 \mathrm{~m}$ from one another and distributed across the different successional stages of the forest fragment (Fig. 1). We did that to verify how forest structure and the surrounding matrices would affect the attraction of frugivores to the feeders.

Half of the feeders consisted of a wooden tray $(50 \times 30 \mathrm{~cm})$ attached at the top of a $1.8 \mathrm{~m}$ wooden pole (suspended feeders), intended to attract birds, bats, and scansorial frugivores (opossums, primates). A plastic dish (40 cm diam.) was laid on the ground (ground feeders) in the remaining stations, 
intended to attract medium to large terrestrial frugivores, without excluding the flying and scansorial ones. In 10 out of 32 feeders, fleshy native fruits were supplied weekly, and the frugivores' visits were monitored by a trail camera (Bushnell, model 119,436) attached to a nearby tree (approx. $1 \mathrm{~m})$. Every week, the ten cameras were transported to different stations so that each station was sampled at least one week per month.

Because we aim to support native biodiversity maintenance in our study area, we avoid exotic species. Exotic plant species can lead to competition with natives for space, nutrient and dispersers (Rowles and O'Dowd 2009), promote landscape biodiversity homogenization, and alter ecosystem functions (Vitousek et al. 1997; Alberti et al. 2017). Thus, fruits were collected in other sites in the same region and represented species native to the Atlantic forest of southeast Brazil.

The same feeding station was never supplied with fruits in subsequent weeks, to avoid animal food habituation. Food habituation can lead to long-term problems such as obesity (Auman et al. 2008), low mobility behavior (Ottoni et al. 2009), and low reproductive success (Pierotti and Annett 1991). As we depended on an irregular availability of fruit species over time, the identity and number of fruits offered in the feeders were unpredictable due to differences in fruit phenology. In the supporting information, Table S1 is available to show the fruit offering schedule, the experimental week, month, fruit family, species, number of fruits offered in that week, and their provenance. Weekly, whenever possible, we tried to evenly distribute the number of fruits among the tenfeeding stations. When fruit shares were small (see week 8 for Eugenia selloi at Supporting information: Table S1), we prioritized a partition that encompassed equally the two forests structures, and we randomly selected the feeder height.

After being triggered by any animal movement, the trail cameras were set to record for $45 \mathrm{~s}$ with a $5 \mathrm{~s}$ interval between shots, a continuous function, and the date and time function activated (Paredes et al. 2017). The consumer species were identified, and the number of fruits and seeds ingested counted. As subsequent $45 \mathrm{~s}$ video shots are not temporally independent, we considered a "visit" by a frugivore only those video shots separated, on the same day and in the same station, by a $30 \mathrm{~min}$ interval (Paredes et al. 2017).

For each fruit species offered in the feeders, we recorded the following morphometrics: pulp, seed, and total mass; maximum and minimum fruit diameter; mean seed number; maximum and minimum seed diameter (Supporting information: Table S2). We characterized the surrounding matrix closest to each feeding station into five categories (residential, standing sugarcane plantation, harvested sugarcane plantation, vegetated area, and management trails). We also assigned the forest structure in which each feeding station was located as early and late-successional. We classified visits by consumers into four different fruit-handling types: Pulp Mashing Visit (PMV), when the animal consumed the pulp entirely or in part but left the seed on the tray; Fruit Consuming Visit (FCV), when the whole fruit was ingested or removed from the tray with the beak, paws, or mouth, beyond the camera field vision; Non-consuming visit (NCV), when the animal only smelled or manipulated the fruit in the tray without consuming it; Non-fruiting visit (NFV), when the animal visited an empty tray.

\section{Statistical analysis}

\section{Models of seed ingestion probability (SIP) and space use patterns (SUP)}

To answer whether some fruit traits influence their chance to be dispersed away from the study stations (FCV) and whether that chance varies according to animal vector, GLMM was
Fig. 1 Map locating the Santa Genebra fragment in São Paulo state and in Brazil. On the Santa Genebra map are indications of the sampling point locations regarding forest structure. a: Brazil, b: São Paulo state, c: Santa Genebra. (Figure made using Qgis 3.4)

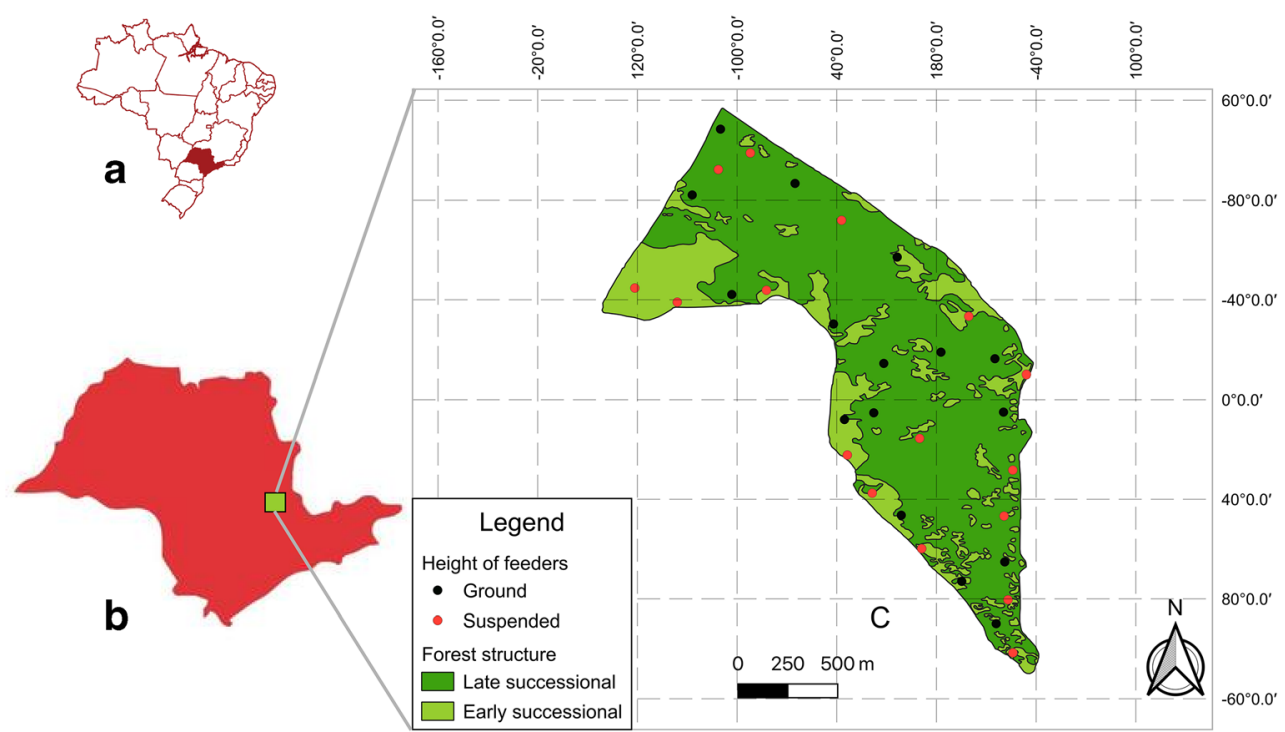


used with a binomial error distribution and a logit link function. As fixed factors, we utilized measured fruit attributes, fruit abundance on the feeder, forest structure, surrounding matrices, and feeder height. We utilized as random factors: plant and frugivorous taxonomy (species and family), month and season of visitation, and feeder's identity (see Table 1). Species were nested within their respective families and months within seasons. With a binary response variable (ingested $=1$, not ingested $=0$ ). Ingested $(=1$ ) including only Fruit Consuming Visits (FCV) and not ingested (=0) including both Pulp Mashing Visit (PMV) and Non-Consuming Visit (NCV). This model is hereafter called SIP.

SIP model was performed first to three taxa separately and, then, the analysis was made at the level of species considering only ones that did consume fruits (FCV). The SIP model for the species-level analysis removed frugivorous taxonomy (species and family) as a random factor.

A GLMM with a Poisson error distribution and a log link function was performed to determine the visitor's space use. As fixed factors, we utilized the height of feeders, forest structure, and matrix. We utilized as random factors: plant taxonomy (species and family), month and season of visitation, and feeder's identity (see Table 2). Species were nested within their respective families and months within seasons. For the response variable, we considered the sum of Fruit-Consumer Visits (FCV), Pulp Mashing Visit (PMV), and Non-consuming visit (NCV) per feeder. This model is hereafter called SUP.
SUP model was performed first to all frugivores altogether and then at a species level. Because the study aims to investigate the frugivorous residual fauna, we consider for specieslevel analysis only visitors that consumed any fruit.

The final SUP and SIP models were obtained by a Backward selection of the fixed factors only - the random structure was maintained thoroughly in all models (Barr et al. 2013). Starting from the full model, we used the likelihood ratio test to remove the fixed factors that do not contribute significantly to the model fit (Crawley 2013). The likelihood ratio test compared the likelihood of the data under the full model against the likelihood of the data under a model with fewer factors and was performed using an analysis of variance (ANOVA) performed by the Anova function. In each step, we removed the fixed factors that explained a small part of the deviance. The $p$-values reported to each selected model are related to Anova, type III Wald chi-square tests (using Package car version 3.0-2) (Fox et al. 2016). All analyses were performed using $R$ ( $R$ Development Team 2020).

\section{Visitation and fruit phenology dynamics}

We compared the monthly abundance of frugivorous visits with the number of plant species bearing zoochorous at SG made by Morellato (1991). We did this to verify the consequences of fruit seasonality on the feeder visitation.
Table 1 Fixed and random variables employed in the SIP model

\begin{tabular}{lll}
\hline SIP model's structure & Variables & Categories \\
\hline Fixed Factors & Measured fruit attributes & Fruit and seed diameter \\
& Pulp, fruit and seed mass \\
& Fruit abundance on feeder & Seed number per fruit \\
Matrix & - \\
& Residential \\
& Standing sugarcane plantation \\
& Harvested sugarcane plantation \\
& Forest structure & Management trails \\
& Early successional \\
Height of feeders & Late successional \\
& Suspended \\
Season & Ground \\
& Fet (October to March) \\
Frugivorous species & Dry (April to September) \\
Feeders & Fonth & 32 feeders \\
Fruit family & See Supporting Information: Table S1 \\
& See Supporting Information: Table S1 \\
& See Supporting Information: Table S1 \\
\hline
\end{tabular}


Table 2 Fixed and random variables employed in the SUP model

\begin{tabular}{lll}
\hline SUP model's structure & Variables & Categories \\
\hline Fixed factors & Matrix & Residential \\
& & Standing sugarcane plantation \\
& Harvested sugarcane plantation \\
& Forest structure & Vegetated areas \\
& Management trails \\
& Height of feeders & Early successional \\
& Late successional \\
Random factors & Suspended \\
& Fruit family & Ground \\
& Fruit species & See Supporting Information: Table S1 \\
& & See Supporting Information: Table S1 \\
& & \\
\hline
\end{tabular}

\section{Graphic network}

Network visualization and modularity analysis were performed in the igraph R package (Csardi and Nepusz 2006). Network modules were recovered by using the Louvain method (Blondel et al. 2008).

\section{Results}

We recorded 21 frugivorous species belonging to three different classes (Aves, Mammalia, and Reptilia). Sixteen of them interact with 21 fruits species belonging to 12 different families in $36,280 \mathrm{~h}$ of camera trap effort (Supporting Information: Fig. S1). The most frequently recorded bird and mammal species were, respectively, Turdus leucomelas (Turdidae) and Didelphis albiventris (Didelphidae). The only reptile species recorded was Salvator merianae (Teiidae). Together, $T$. leucomelas and $D$. albiventris were recorded in $53 \%$ of all visits. The six species that were most likely to remove fruits from the feeders (i.e., considering only FCV visits) were $T$. leucomelas, Sapajus nigritus (Cebidae), S. merianae, Penelope obscura (Cracidae), Pitangus sulphuratus (Tyrannidae), and Ramphocelus carbo (Thraupidae) (Fig. 2).

Most of FCV (Fruit-consuming visits) had minimal overlap in the size of ingested fruits, therefore displaying complementary functions in seed dispersal (Fig. 3). Although P. obscura was not the most frequently species recorded in the videos, it explored a wide range of fruits (fruit diameter 4.14$23 \mathrm{~mm}$ ), contrasting to T. leucomelas, which was more prevalent at the feeder but fed on a more selective range of fruits (fruit diameter 4.14-13.98 mm).

The network modules indicated a subset of frugivores that interact more with a particular plant species, forming groups (Ramos-Robles et al. 2016). A modular organization emerged between the Fruit Consumer Visitors, FCV, (10 animals' species), and the fruit species they ingested (15 plant species). Module A is composed of five generalist bird species (T. leucomelas, T. amaurochalinus, T. rufiventris, $P$. sulphuratus, and $R$. carbo) consuming mainly the small fruit of Schinus terebentifolius (fruit diameter 4.14$4.60 \mathrm{~mm}$ ). Module B is formed solely by the specialist bird Penelope obscura, which was the only consumer of Vitex megapotamica. Penelope obscura shared consumption of large fruits with individuals of other modules. Garcinia brasiliensis (fruit diameter 21.28-22.04 mm) with Sapajus nigritus and Eugenia pyriformis (fruit diameter 28.52$30.10 \mathrm{~mm}$ ) with Salvator merianae. Module C is composed of the two mammals (D. albiventris and S.nigritus) that shared the consumption of Solanum diploconos, a fruit whose maximum diameter was $30.41 \mathrm{~mm}$. Finally, Module D encompassed a small bird (Saltator similis) and a lizard (Salvator merianae) that shared the consumption of Eugenia cauliflora (maximum diameter $12.10 \mathrm{~mm}$ ). Salvator merianae was the only consumer of Cissus verticilata (maximum diameter $7.61 \mathrm{~mm}$ ) (Fig. 4).

Our SIP (Seed Ingestion Probability) model indicated that the fruit abundance on the feeder determining the seed ingestion probability for birds $\left(p=0.003\right.$, estimate $=0.021, \mathrm{X}^{2}=$ 8.766). For mammals, the fruit diameter was the most important factor $\left(p=0.306\right.$, estimate $\left.=0.204, \mathrm{X}^{2}=4.674\right)$ (Fig. 5). For birds, the chance of the fruit ingestion increases with more fruits on feeders, whereas for mammals, the increase of fruit diameter increases the chance of dispersing. Neither of the fixed factors was significant for reptiles (Supporting Information: Table S3).

We also explored seed ingestion probability at the species-level for fruit consumers. For Turdus leucomelas, "seed diameter" $\left(p=0.016\right.$, estimate $=0.3942, X^{2}=$ $5.769)$ and "fruit diameter" $(p=0.002$, estimate $=$ $\left.-0.5364, X^{2}=13.192\right)$ were identified as additional factors that explained seed ingestion. (Supporting 
Fig. 2 Illustration of the main fruit-consumers on the suspend feeder (a) and ground feeders (b). The bar graph indicates the proportion of Fruit-consuming and Pulp-mashing visits. (Painting made by Fernando Igor and Graph made in R studio, using ggplot 2 package by Wickham 2016)

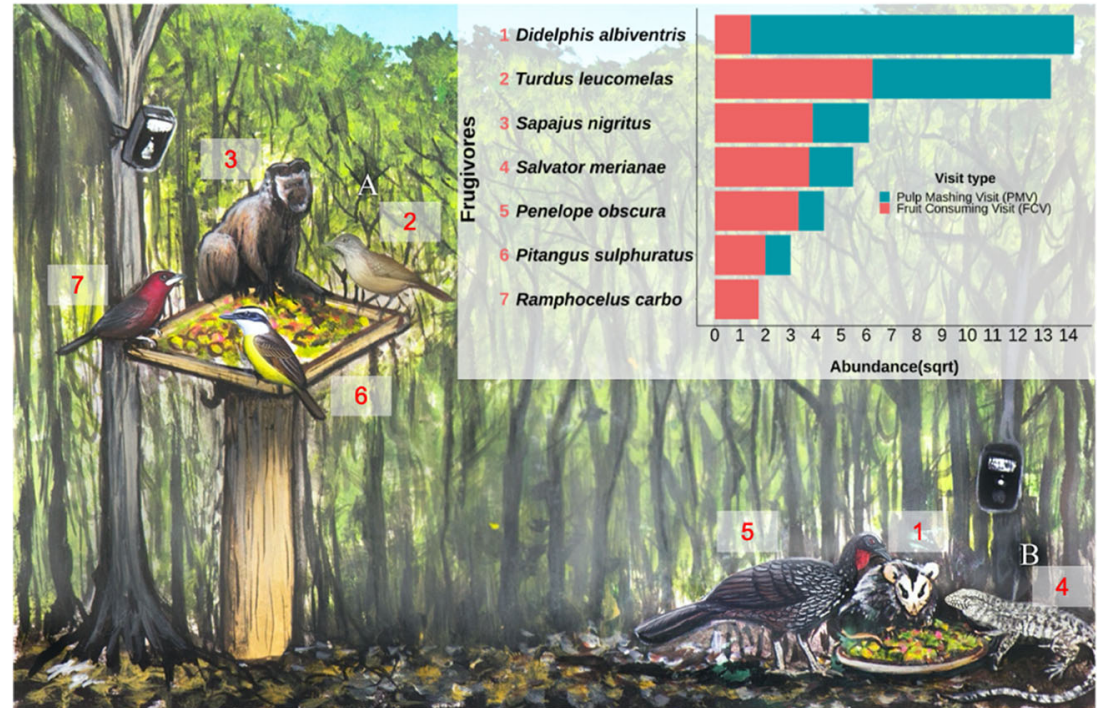

Information: Table S3). For S. nigritus, Didelphis sp., S. merianae, and P.obscura, neither of the fixed parameters was significant for explaining the seed intake. The other FCV visitors could not perform the SIP models due to small visiting sample sizes.

Furthermore, we found a seasonality on visitation records. The most visited month, May, concentrated 129 out of 768 visits records, while in January, only six visits were observed. Indeed, in May we detected the highest visitation records on the feeding stations of T. leucomelas, P. sulphuratus, and the unique record of $T$. rufiventris. At the same time, D. albiventris and $T$. leucomelas displayed little variation in their visitation patterns across months. The visits of $S$. nigritus, $S$. merianae, and $P$. obscura were clustered in time, and $P$. sulphuratus, $R$. carbo, S. similis, T. amaurochalinus, and T. rufiventris were more opportunistic, with occasional visits at the feeders (Fig. 6).
Our SUP model indicates that the height of feeders ( $p=$ $7.719 \mathrm{e}^{-} 06, \mathrm{X}^{2}=8.90$ ) explains visitation abundance for all visitors altogether (Supporting Information: Table S4). We also explored the visitation abundance of Fruit- Consumer Visitor (FCV) individually. For Turdus leucomelas, the most important variable was matrix $\left(p=0.0003, \mathrm{X}^{2}=36.84\right)$. In particular, the residential matrix contributed more to explain the visits (estimate $=1.36, p=1.33 \mathrm{e}-07$ ). Likewise, Sapajus nigritus' visits were explained by the matrix $\left(p=7.83 \mathrm{e}^{-} 07\right.$, $\mathrm{X}^{2}=33.8935$ ), with residential matrix contributing more to visits (estimate $=1.32, p=2.42 \mathrm{e}-07$ ). For $D$. albiventris, the abundance of visits responded to "Height of feeders" ( $p=$ $\left.0.002, X^{2}=9.357\right)$, negatively influenced by suspended feeders (estimate $=-0.7206, \mathrm{p}=0.002$ ) (Supporting Information: Table S4). For S. merianae and P.obscura, neither of the fixed parameters was significant, and, for the other FCV visitors, small visiting sample sizes precluded the performance of SIP models.
Fig. 3 Graph indicating the diameter variation of fruits consumed by the frugivores in comparison with the overall fruit offering. The frugivores are divided in colours according to the taxa, as shown in the legend. (Figure made in R studio, using ggplot 2 package)

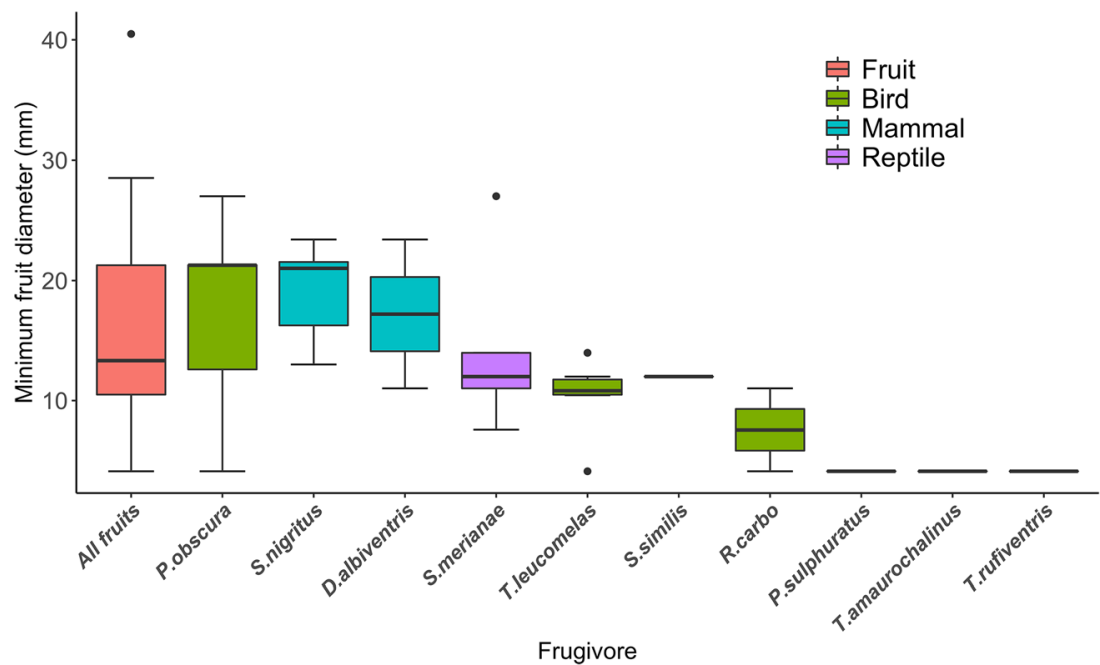




\section{- Fruits \\ - Birds \\ Mammals \\ - Reptiles}

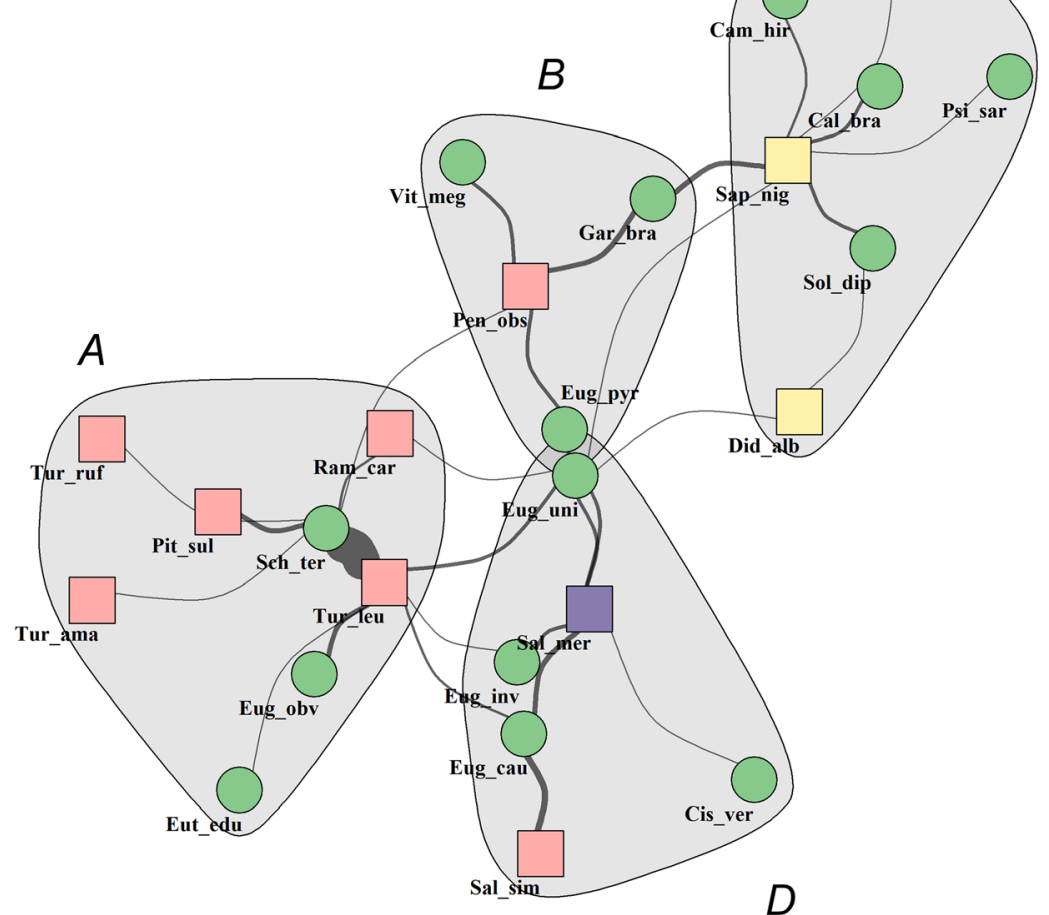

Fig. 4 Modular network interactions between seed dispersal frugivores and fruits. The size of links is proportional to the number of fruitinteractions. Birds: Pit_sul: Pitangus sulphuratus, Tur_ama: Turdus amaurochalinus; Tur_ruf: Turdus rufiventris; Tur_leu: Turdus leucomelas; Ram_car: Ramphocelus carbo; Sal_sim: Saltator similis; Pen_obs: Penelope obscura; Reptile: Sal mer: Saltator merianae; Mammals: Did alb: Didelphis albiventris; $\bar{S}$ Sap nig: Sapajus nigritus. Fruit species: Eug_obv: Eugenia obversa; Eut_edu: Euterpe edulis;
Sch ter: Schinus terebinthifolius; Eug cau: Eugenia cauliflora; Eug inv: Eugenia involucrata; Cis_ver: Cissus verticillata; Eug uni: Eugenia uniflora; Eug_pyr: Eugenia pyriformis; Vit_meg: Vitex megapotamica; Gar_gar: Garcinia brasiliensis; Sol_dip: Solanum diploconos; Cal_bra: Calophyllum brasiliense; Psi_sar: Psidium sartorianum; Ran_arm: Randia armata; Cam_hir: Campomanesia hirsuta. (Figure made in R studio, using igraph by Csardi and Nepusz (2006))
Fig. 5 Graph with a slope and intercept from GLMM models, indicating the influence of fruit abundance in Birds and fruit diameter in Mammals on seed probability of being dispersed $(1$ = ingested; not- ingested $=0)$. (Figure made in R studio, using ggplot 2 package)
Birds

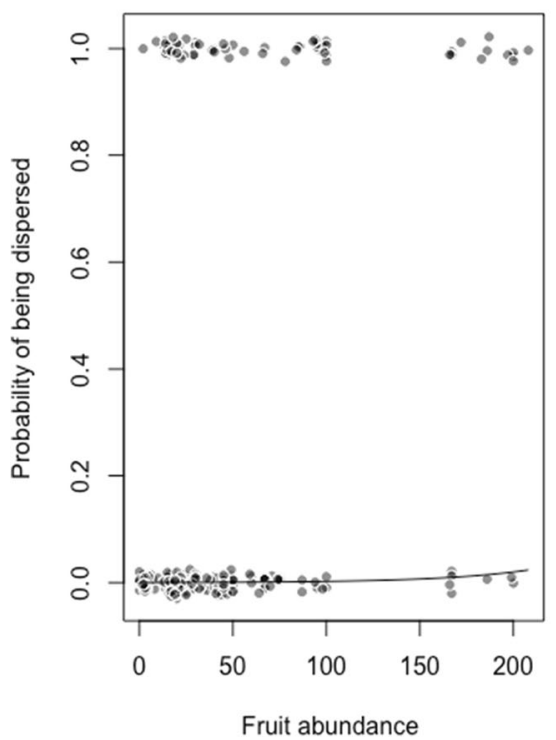

Mammals

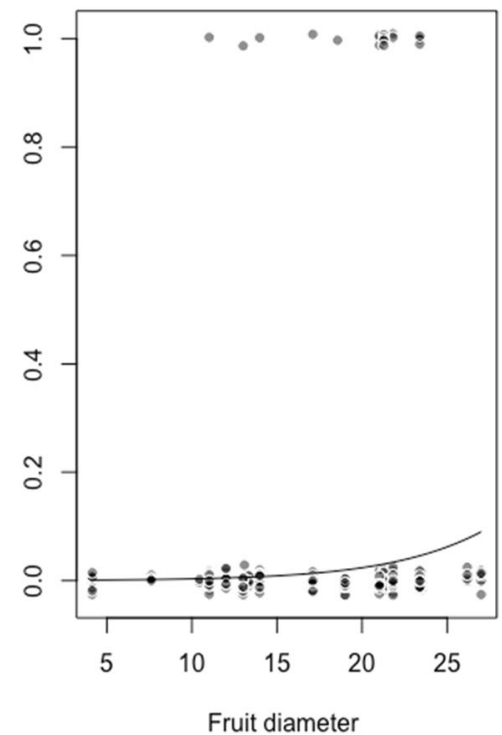




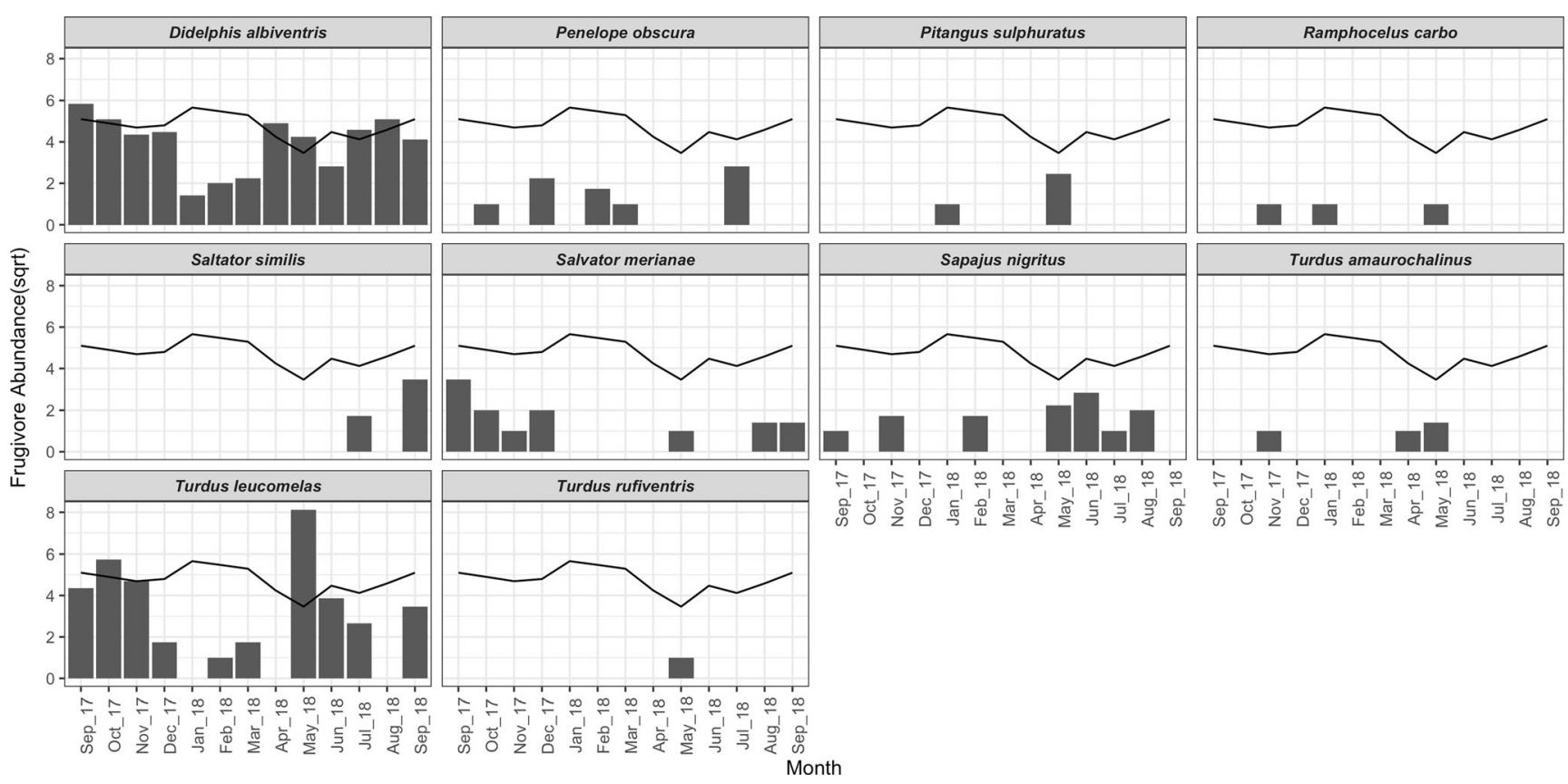

Fig. 6 FCV visitors' monthly abundance (sqrt transformed) and the fruit phenology seasonality by Morellato (1991). (Figure made in R studio, using ggplot 2 package)

\section{Discussion}

Establishing a link between fauna and flora in the process of habitat enrichment and restoration is one of the major challenges in current ecology studies (Howe 2016; MorenoMateos et al. 2020). Our study recorded 16 species, very resilient and widespread across fragments of Brazilian Atlantic Rain Forest, such as The Black-horned capuchin (S. nigritus), Pale-breasted Thrush (T. leucomelas), The Black and white Tegu (S. merianae), and The Dusky-Legged Guan ( $P$. obscura), interacting with 21 native fruit species during one year of field observation. In general, birds consumed a wider variety of fruits, while mammals and reptiles favored the large fruits more. The overall visits were more abundant during the dry season.

To our knowledge, our sampling effort was 23 times greater than typical frugivory studies carried out in the Brazilian Atlantic Forest (Hasui et al. 2018), that generally use focal approaches. Focal approaches may have limitations on data collection due to the dependency on intensive human effort on the field, which is not always feasible and may not differentiate mere visitors from consumers, especially in dense vegetation and non-volant animals (Prasad et al. 2010). The use of a camera trap overcomes such problems and also allowed us to achieve a rare ecology scale on frugivore studies, the community level. Typically, in frugivore studies, a single taxon of dispersal vectors (e.g., primates, bats, ants, birds) is considered, either in Neotropics (Andresen et al. 2018) and in urban fragments, where the seed disperser community remains mostly unstudied (Gelmi-Candusso and Hämäläinen 2019).
The two most frequent visitors to the feeders were the PaleBreasted Thrush and the White-Eared Opossum. These animals occupy different frugivore spectrum positions, with fruit representing up to $90 \%$ of the Thrush diet (Gasperin and Pizo 2009) while offering only an opportunistic food source to the Opossum (Cáceres 2002). Although the White-eared Opossum behaved mostly as a pulp mash visitor and the Pale-Breasted Thrush as a fruit consumer visitor, for both are reports of undamaged seeds in the feces with improved germination (Cáceres 2002; Gasperin and Pizo 2009). In opossums, this phenomenon is more prevalent only with small seeds (Traveset 1998). However, many areas of Atlantic Rain Forest as SG are defaunated. Over-abundant generalist animals (e.g., opossum) can be employed in habitat enrichment by pulp-cleaning large fruits, preventing microbial damage to seeds (Traveset et al. 2007, Cantor et al. 2013). Or by adequate enrichment approaches (Hale and Swearer 2017), such as the Induced Seed Dispersion technique (ISD) (Silva et al. 2020). ISD consists of inserting small seeds of selected species in attractive fruits, such as banana (Musa sp.), which are offered to local residual frugivores that can ingest and disperse hundreds of seeds in the habitat, promoting flora enrichment (see Silva et al. 2020).

\section{Frugivores seed ingestion probability (SIP model)}

We found an increase in the fruit ingestion probability for birds when more fruits were on the feeders. The positive relationship might be explained first by the increased visual appeal when the fruits were more abundant which increased the 
fruits' conspicuity (Martin Schaefer et al. 2007), but also as a chromatic contrast, making them more attractive for visually oriented birds (Ordano et al. 2017). Such visual appeal could decrease neophobia from feeders, acting as a signal of a less dangerous resource than if a single or few fruit specimens were found (Greenberg and Mettke-Hofmann 2001). As most of the avian species that attended our feeders tended to swallow the fruit, more birds' visits were translated into more seed ingestion (FCV visits).

For mammals, we found a positive relationship between fruit diameter and seed ingestion probability, featuring some complementarity in the dispersal role between mammals and birds. Whereas birds are mostly limited by the gape-width and seed ballast, mammals, on the other hand, are not, mainly because they are larger, and most do not fly, allowing the consumption of large propagules (Howe 1986). In these large propagules, mammals can find more pulp enriched with more nutrient-rewards (Howe 1986). Also, scent plays a crucial role in fruit detection in many mammal groups (van der Pijl 1982; Valenta et al. 2017; Melin et al. 2019), indicating that different fruit syndromes can be explored among birds and mammals in fruit feeders. Mammals' digestion is usually longer than in most birds, allowing seeds to stay longer in their guts, which eventually can increase seed shadow and connect plant populations (Fragoso 1997; Steele et al. 2011; Tsunamoto et al. 2020). In terms of ecological restoration, the combined effect of birds and mammals' dispersion is indispensable to increase habitat enrichment.

\section{Frugivorous space use patterns (SUP model)}

The Space Use Patterns models suggest that " Height of feeders " significantly impacts the visitation abundance, which is intriguing since matrix and forest structures are considered key to explaining species distributions in fragmented areas (Boesing et al. 2018; Melito et al. 2018). A reason for that lies in the natural history of the most abundant visitors. Most of them are generalists, which means that they subsist in several habitats with different degradation stages, allowing broader distributions in anthropogenic landscapes (Pizo 2004; Cantor et al. 2013), making the height of the feeders the only constraints to the visitation. This generalist habit is fundamental to regeneration in urban habitats because fauna can promote seed exchanges among different green patches in the urban landscape, acting as habitat connectors. This connection is essential to maintain local and regional plant diversity (Zhou and Chen 2010)- indicating that feeders, as we employed here, could affect beyond the limits of the offering site.

The seasonality also influenced the visits, with most being recorded in the dry season, a period in Atlantic Rain Forest ranging from April to September. During this dearth, the availability of natural food resources is limited, especially fruit. Moreover, fruit shortage can be very pronounced in heavily degraded areas as SG (Morellato 1991) due to the depletion of zoochoric plants (Galetti 1993). Salvator merianae (Reptilia), S. nigritus (Mammalia), P. sulphuratus (Aves), and T. rufiventris (Aves) were absent from our records (except for the latter, recorded once) for at least two months before the dry season, and then, reappeared on the feeders, after that, searching for food indicating that visits increased during the decrease in natural food resources, as observed for urban birdfeeders in temperate zones (Cox et al. 2016; Galbraith et al. 2017). This marked seasonality in fruit resource represents an opportunity for the implementation of ecological restoration programs based on fruit feeders, because frugivores expand their foraging areas, tend to risk more to find food, and can consume less preferred fruits when the preferred ones are a limited resource in the area (Foster 1977; Morris 1989). Nevertheless, it is important to choose the right plant species, prioritizing those that have multiple fruiting peaks throughout the year or those that fructify in dry periods. Minimizing the dearth phase is vital in areas under restoration process to attract and sustain local frugivorous at all times of the year (Howe 2016). Moreover, native plant species are desirable in restoration programs, since exotic ones could compete for space, nutrients, and dispersers, leading to flora homogenization and loss of ecosystem functions (Alberti et al. 2017; Rowles and O’Dowd 2009).

Both SIP and SUP models reinforce the importance of considering a robust natural history component on restoration and flora enrichment. Through the comprehensive knowledge of the local fauna, it is possible to direct adequate efforts and promote efficient, locally restoration through the ecological interactions.

\section{Sapajus nigritus}

The Black-Horned Capuchin is an endemic primate of the Brazilian Atlantic Rain Forest (Vilanova et al. 2005). They play essential roles such as seed dispersal and pest control in many fragments and urban forests, where they may still be one of the few remaining medium-sized fruit-eating mammals (Chiarello 1999).

Even among the most abundant feeder's visitors, the black horned Capuchin's importance is very significant. In our network graph, they were placed together with the white-eared Opossum, forming the Mammalian module, mainly due to the consumption of Solanum diploconos, a fruit of $30 \mathrm{~mm}$ maximum diameter. As a group, mammals are indispensable to seed dispersal in tropics (Tabarelli and Peres 2002). However, Sapajus nigritus consumed the widest variety of fruits. Indeed, most of their visits were for fruit consumption, different from the Opossum, a mostly pulp-masher visitor. In comparison with birds, both Capuchins and Guans consumed the widest variety of larger propagules $(<13 \mathrm{~mm})$. Unlike the Guan, the 
Black-horned Capuchin is more curious and fearless to explore the feeders, which was translated into more visits and consumption in our experiment (EDB Rigacci, pers. obs.).

The Black-horned Capuchin lives in structured groups under a limited home range (Fragaszy et al. 2004). Most of these groups at SG are established close to residential zones, exploring feeders in these regions as indicated in our SUP models, and observed in other fragments (Ludwig et al. 2006; Mikich and Liebsch 2014a). This differential space use is related to natural food resources' availability in degraded remnants, which could be scarce and unpredictable (Galetti 1993). In these adjacencies, Capuchins can complement their diet with leftovers, orchards, sugarcane, and corn-crops. The SG neighborhood residents often relate Human-Primate conflicts, with capuchins groups invading the nearby houses to steal food (EDB Rigacci, pers. obs.), as reported in similar situations (see Freitas et al. 2008; Ludwig et al. 2006). The techniques of environmental enrichment through fruit supplementation could either promote the ecological restoration and promote a peaceful coexistence with humans in peri-urban areas, given that the Capuchins' occurrence on such matrixes is proportionally inverse to the availability of native fruits in surrounding natural patches (Mikich and Liebsch 2014b).

In general, primates play an irreplaceable role as a seed disperser (Gardner et al. 2019). However, they are one of the most threatened vertebrate groups in the tropics, mainly due to land-use changes, habitat loss, and deforestation (Estrada et al. 2017), making their loss catastrophic to forest regeneration. Here, the Black-horned Capuchin is one of the most important seed dispersers. Despite their incredible capacity to adapt to anthropogenic landscapes, they depend on a minimal structured forest cover due to their arboreal habits (Ludwig et al. 2006). Thus, to keep them in urban green patches playing their pivotal functions, it is vital to preserve the forest canopy, maintain a minimum continuum area delimited by their home ranges, and promote habitat enrichment using species that produce canopy.

\section{Turdus leucomelas}

The genus Turdus (Turdidae) encompass the most common frugivorous birds in urbanized landscapes, occurring in Eurasia, Africa, and the Americas (del Hoyo et al. 2005). In the Brazilian Atlantic forest, the Pale-breasted Thrush is one of the most central seed dispersal agents in areas under restoration process (Ribeiro da Silva et al. 2015). In our study site, they were the most abundant fruit-eater and the second to consume the broader fruit richness. The Turdus leucomelas heavily consumed either Schinus terebenthifolius and Euterpe edulis, both plants with small fruits, but with a proportionally large seed. Our SIP models suggested the negative influence of the fruit diameter and the seed diameter positive influence on seed ingestion. The fruit diameter's negative effect is well described for fruit-eating birds owing to gape-width limitation (Wheelwright 1985; Pires and Galetti 2020). The found positive correlation is non-obvious since increasing the seed size provides more ballast and occupy a greater gut volume (Martin 1985). Nonetheless, it is possible that the trade-off between seed ballast and nutrient content as lipid and second compounds in the fruit pulp (Cazetta et al. 2008) favored the consumption of fruits with proportionally big seeds, at least for our fruit sample. Indeed, it is known that Neotropical plants that have larger seeds need to compensate the ballast by investing in pulp' nutrients in order to keep pace with their competitive environment (Howe 1986). Since our experiment did not control for fruit chemistry, it is challenging to assume this trade-off as the only reason for these specific choices. Given that the maximum and minimum diameter was, respectively, 11.92 and $8.17 \mathrm{~mm}$ for the consumed fruits, this positive relationship fits the Pale-breasted Thrush gape-width, which is around $12 \mathrm{~mm}$ (Galetti et al. 2013). This physiological constraint prohibits consuming some food items by birds and could be more informative for a well-known generalist bird such as T. leucomelas (Gasperin and Pizo 2009).

Our SUP models indicated that the thrushes proportionally visited more areas close to the residential matrix, a pattern possibly resulted from their generalist habits, that enable them to cross different matrices and confer them low sensitivity to disturbance (Gasperin and Pizo 2009), creating opportunities for exploring new shelters and food sources, both in urban green habitats. This mixed habitat preference has a relevant consequence on plant distribution ranges, allowing a vital seed connection between green patches among themselves and with urban areas (Emer et al. 2018). This capacity to connect different matrices is vital for ecological restoration in urban fragments. It means that even a ubiquitous bird species is essential to ecological restoration and needs to be considered in the conservation agenda, since declines of common species can go unnoticed initially, but represent a disproportional reduction of essential ecosystem functions in urbanized areas (Rosenberg et al. 2019).

\section{Salvator merianae}

The Salvator merianae occupies most South American Biomes and has the broadest geographical distributional among its genus (Péres 2003). The fragmentation of natural habitats has forced them to live in man-modified landscapes, including peri-urban areas. In these areas, The Black-andwhite Tegu finds food, shelter and acts as a seed disperser (Lopes and Abe 1999). On the other hand, as a group, reptiles are frequently underrepresented in frugivory studies, with fruit diet masked under the general category of "vegetative or plant matter," lacking detailed information on fruit identity and quantity (Valido and Olesen 2007). Here, The Black-andWhite Tegu was the third most recorded fruit consumer. 
We did not identify any significant factor that determined the seed ingestion in our model. Nevertheless, as in mammals, gape-width and seed ballast are not a constraint for Salvator merianae, allowing exploration of a wide range of fruits. Traveset (1998) found that of 41 plant species consumed by the Black-and-White Tegu, one third had an increased germination rate, and more than half indicated no change in germination. Increases in germination speed were also found for half the species, reinforcing their importance on seed dispersal function. Further, their territorial habits could promote nongregarious populations, representing a more scattered seed deposition through their feces (Péres 2003), decreasing the competition between the seedlings and increasing plant survival rates (Jordano et al. 2007).

We perceived that the Tegu's visits were more abundant during the wet season, which is different from what we observed for most frugivores. This difference is due to brumation, a dormancy period with minimal metabolic activity, in which reproduction and foraging are drastically reduced or null (Beolens et al. 2011). In terms of habitat enrichment, this is important to better divide the efforts in offering some particular types of fruits year-round, since Tegu can consume large fruits, for example.

Salvator merianae has become conspicuous, especially in urban forest fragments, but because its fruit diet is still poorly studied, it is essential to reinforce them as important seed dispersers. Thus, accounting for them in ecological restoration and conservation programs of urban areas is indispensable (Corlett 2017).

\section{Penelope obscura}

The Guans can be found across most Neotropics, in forests of different conservation status (Brooks and Strahl 2000), where they can act as important seed dispersal agents (Howe 1984). The Dusky-Legged Guan is considered one of the few resilient medium-size frugivores bird in many Brazilian Atlantic Rain Forest remnants (Mikich 1996). They usually occupy and forage in the canopy on the forest interior. Their diet is heavily based on fruits during most of the year, and during the dry season, due to fruit shortage, they consume other plant items such as flowers and leaves (Zaca et al. 2006).

Guans were the only fruit-eating animal clustered alone in a module in our network graph representation. Given that modules typically reflect morphological and behavioral features of dispersal agents and fruits (Howe 2016), it is possible to indicate the Guans' unique characteristics and importance in our experiment. Their size and large gape allowed an exploration of the broadest range of fruit size, from small such as Schinus therebentifolius $(4.14 \mathrm{~mm})$ to larger ones such as Eugenia pyriformis $(28.52 \mathrm{~mm})$. Additionally, the absence of a gizzard keeps seeds undamaged in their guts (Guix 2006), which indicates a greater chance of seed germination and establishment for the wide variety of fruits species they consume.

Like the Capuchins, Guans are heavily forest-dependent. Habitat loss, fragmentation, and illegal hunting have threatened them in many forest fragments (Smith and Derna 2015). As our network graph indicated, the loss of them in these green patches represents the loss of an incomparable role in seed dispersal, precluding the ecosystems' capacity to maintain their ecological functions.

\section{Sampling Station visiting pattern}

Our models and our network graphics document the critical role of fauna in the process of habitat enrichment and regeneration. The Capuchin, the Tegu, and the Guan are essential in providing large-seeded trees' dispersal, a role that is extremely important to the maintenance of diversity and ecosystem services and can perform climate change mitigation in urban forests. Without these medium-sized dispersers, only smallseeded and abiotically-dispersed trees will have a chance to establish; such species are less carbon-dense, representing a significant decrease in carbon storage and sequestration in the medium and long term (Gardner et al. 2019). Nevertheless, small- and medium gapesized generalist birds as the Pale-breasted Thrush, the Silver-beaked Tanager, and the Great Kiskadee are essential as well. They connect plant populations between green patches and urban fragments (Culley et al. 2007), increasing and maintaining diversity and resilience for all fauna populations, including the more specialist ones (Tylianakis et al. 2010).

Lastly, through fruit feeders, we stressed the fauna's importance in ecological regeneration and in maintaining fundamental ecological interactions in a defaunated fragment in the Brazilian Atlantic Forest realm. The Atlantic Forest is a biome with one of the highest rates of above-ground carbon sequestration potential for restoration areas (Cook-Patton et al. 2020) and is currently composed of small, isolated remnants, mostly surrounded by urban landscapes (Ribeiro et al. 2009). Maintaining urban forests is necessary to maintain the many resources provided by the ecosystem services, such as water balance, climate regulation, spiritual and recreational ones, to millions of urban citizens (GómezBaggethun and Barton 2013; Timilsina et al. 2014; Estevo et al. 2017). In the Brazilian Atlantic Rain forest, more than 125 million people are benefited from these services, including relevant metropolitan areas such as São Paulo and Rio de Janeiro (Martinelli et al. 2013). 
We know that much more needs to be done to improve habitat quality in the anthropogenic landscape in a constant state of degradation. Shedding light on the potential of the resilient fauna is the first step in promoting a comprehensive view on ecological restoration based on ecological interactions.

Supplementary Information The online version contains supplementary material available at https://doi.org/10.1007/s11252-020-01080-5.

Acknowledgments We thank Kim MacConkey and Jennifer H.M Myers for the useful comments and suggestions, Marcela Barbosa for the mapmaking; Fernando Igor for painting of the Fig. 2; Nathalia Sigolo for the fruit measurements; Fundação José Pedro de Oliveira and ICMBIO (Instituto Chico Mendes de Conservação da Biodiversidade) for allowing our study in the Santa Genebra. E.D.B.R, N.D.P and G.M.F received a research scholarship from Conselho Nacional de Desenvolvimento Científico e Tecnológico (CNPq).

Author's contribution E.D.B.R and W.R.S performed the field and laboratory work. E.D.B.R, G.M.F and N.D.P performed the statistical analysis. All authors draft the manuscript. All authors revised the manuscript and gave final approval for publication.

Funding E.D.B.R, N.P.M and G.F received a research scholarship from Conselho Nacional de Desenvolvimento Científico e Tecnológico $(\mathrm{CNPq})$. Furthermore, this study was financed in part by the Coordenação de Aperfeiçoamento de Pessoal de Nível Superior - Brasil (CAPES) -Finance Code 001.

Data availability All videos recorded are deposited in LIVEP library (Laboratory of Vertebrates-Plant interaction) at University of Campinas. All the data material is available from the corresponding author on reasonable request.

\section{Compliance with ethical standards}

Conflict of interest/ competing interests The authors declare that they have no conflict of interest.

Ethics approval Legal authorizations to conduct this study were emitted by the Instituto Chico Mendes de Conservação da Biodiversidade ICMBio (License SISBIO: 58921-1).

Consent for publication I Eduardo Delgado Britez Rigacci give my consent for Urban Ecosystems publish my manuscript entitled: "The resilient frugivorous fauna of an urban forest fragment and its potential role in vegetation enrichment".

Code availability Not applicable.

\section{References}

Alberti M, Correa C, Marzluff JM, Hendry AP, Palkovacs EP, Gotanda KM, Hunt VM, Apgar TM, Zhou Y (2017) Global urban signatures of phenotypic change in animal and plant populations. Proc Natl Acad Sci 114(34):8951-8956. https://doi.org/10.1073/pnas. 1606034114
Aleixo A, Vielliard JME (1995) Composição e dinâmica da avifauna da Mata de Santa Genebra, Campinas, São Paulo, Brasil. Revista Brasileira de Zoologia 12:493-511 (English abstract). https://doi. org/10.1590/S0101-81751995000300004

Andresen E, Arroyo-Rodríguez V, Ramos-Robles M (2018) Primate seed dispersal: old and new challenges. Int J Primatol 39(3):443-465. https://doi.org/10.1007/s10764-018-0024-Z

Auman HJ, Meathrel CE, Richardson A (2008) Supersize me: does anthropogenic food change the body condition of silver gulls? A comparison between urbanized and remote, non-urbanized areas. Waterbirds 31(1):122-126. https://doi.org/10.1675/15244695(2008)31[122:SMDAFC]2.0.CO;2

Barr DJ, Levy R, Scheepers C, Tily HJ (2013) Random effects structure for confirmatory hypothesis testing: keep it maximal. J Mem Lang 68:1-43. https://doi.org/10.1016/j.jml.2012.11.001

Benayas JMR, Bullock JM, Newton AC (2008) Creating woodland islets to reconcile ecological restoration, conservation, and agricultural land use. Front Ecol Environ 6(6):329-336. https://doi.org/10. 1890/070057

Beolens B, Watkins M, Grayson M (2011) The eponym dictionary of reptiles. John Hopkins University Press, Baltimore ISBN-10:14214-0135-5

Birch JC, Newton AC, Aquino CA, Cantarello E, Echeverría C, Kitzberger T, Schiappacasse I, Garavito NT (2010) Costeffectiveness of dryland forest restoration evaluated by spatial analysis of ecosystem services. Proc Natl Acad Sci 107(50):2192521930. https://doi.org/10.1073/pnas.1003369107

Blondel VD, Guillaume JL, Lambiotte R, Lefebvre E (2008) Fast unfolding of communities in large networks. J Statistic Mechan: Theory Exper 2008(10):P10008. https://doi.org/10.1088/17425468/2008/10/P10008

Boesing AL, Nichols E, Metzger JP (2018) Biodiversity extinction thresholds are modulated by matrix type. Ecography 41(9):1520 1533. https://doi.org/10.1111/ecog.03365

Bogoni JA, Peres CA, Ferraz KM (2020) Effects of mammal defaunation on natural ecosystem services and human well being throughout the entire Neotropical realm. Ecosyst Serv 45:101173. https://doi.org/ 10.1016/j.ecoser.2020.101173

Brancalion PH, Bello C, Chazdon RL, Galetti M, Jordano P, Lima RA, Medina A, Pizo MA, Reid JL (2018) Maximizing biodiversity conservation and carbon stocking in restored tropical forests. Conserv Lett 11(4):e12454. https://doi.org/10.1111/conl.12454

Brancalion PH, Meli P, Tymus JR, Lenti FE, Benini RM, Silva APM, Isernhagen I, Holl KD (2019) What makes ecosystem restoration expensive? A systematic cost assessment of projects in Brazil. Biol Conserv 240:108274. https://doi.org/10.1016/j.biocon.2019.108274

Brooks DM, Strahl SD (compilers) (2000) Curassows, Guans and Chachalacas. Status Survey and Conservation Action Plan for Cracids 2000-2004. IUCN/SSC Cracid Specialist Group. IUCN, Gland, Switzerland and Cambridge, UK. viii +182 pp. ISBN: 9782-8317-0511-8

Cáceres NC (2002) Food habits and seed dispersal by the white-eared opossum, Didelphis albiventris, in southern Brazil. Stud Neotropical Fauna Environ 37(2):97-104. https://doi.org/10.1076/snfe.37.2.97. 8582

Cantor M, Pires MM, Longo GO, Guimarães PR Jr, Setz EZF (2013) Individual variation in resource use by opossums leading to nested fruit consumption. Oikos 122:1085-1093. https://doi.org/10.1111/j. 1600-0706.2012.00070.x

Catterall CP (2018) Fauna as passengers and drivers in vegetation restoration: a synthesis of processes and evidence. Ecol Manag Restor 19:54-62. https://doi.org/10.1111/emr.12306

Cazetta E, Schaefer HM, Galetti M (2008) Does attraction to frugivores or defense against pathogens shape fruit pulp composition? Oecologia 155(2):277-286. https://doi.org/10.1007/s00442-007-0917-6 
Cepagri (2019) (Center for Meteorological and Climatic Research Applied to Agriculture). Available at https://www.cpa.unicamp.br/ graficos. Accessed in 8 March 2019

Chiarello AG (1999) Effects of fragmentation of the Atlantic forest on mammal communities in South-Eastern Brazil. Biol Conserv 89(1): 71-82. https://doi.org/10.1016/S0006-3207(98)00130-X

Cook-Patton SC, Leavitt SM, Gibbs D, Harris NL, Lister K, AndersonTeixeira KJ, Briggs RD, Chazdon RL, Crowther TW, Ellis PW, Griscom HP, Herrmann V, Holl KD, Houghton RA, Larrosa C, Lomax G, Lucas R, Madsen P, Malhi Y, Paquette A, Parker JD, Paul K, Routh D, Roxburgh S, Saatchi S, van den Hoogen J, Walker WS, Wheeler CE, Wood SA, Xu L, Griscom HP (2020) Mapping carbon accumulation potential from global natural forest regrowth. Nature 585(7826):545-550. https://doi.org/10.1038/s41586-0202686-x

Corlett RT (2017) Frugivory and seed dispersal by vertebrates in tropical and subtropical Asia: an update. Glob Ecol Conserv 11:1-22. https://doi.org/10.1016/j.gecco.2017.04.007

Cox DT, Inger R, Hancock S, Anderson K, Gaston KJ (2016) Movement of feeder-using songbirds: the influence of urban features. Sci Rep 6: 37669. https://doi.org/10.1038/srep37669

Core Team (2020). R: A language and environment for statistical computing. R Foundation for Statistical Computing, Vienna, Austria. URL http://www.R-project.org/.

Crawley MJ (2013) The R book second edition. CRAN. https://doi.org/ $10.1002 / 9780470515075$

Cristescu RH, Rhodes J, Frére C, Banks PB (2013) Is restoring flora the same as restoring fauna? Lessons learned from koalas and mining rehabilitation. J Appl Ecol 50(2):423-431. https://doi.org/10.1111/ 1365-2664.12046

Crouzeilles R, Ferreira MS, Chazdon RL, Lindenmayer DB, Sansevero JB, Monteiro L, Iribarrem A, Latawiec AE, Strassburg BB (2017) Ecological restoration success is higher for natural regeneration than for active restoration in tropical forests. Sci Adv 3(11):e1701345. https://doi.org/10.1126/sciadv.1701345

Csardi G, Nepusz T (2006) The igraph software package for complex network research. Inter J Complex Syst 1695(5):1-9

Culley TM, Sbita SJ, Wick A (2007) Population genetic effects of urban habitat fragmentation in the perennial herb Viola pubescens(Violaceae) using ISSR markers. Ann Bot 100:91-100. https://doi.org/10.1093/aob/mcm077

del Hoyo J, Elliott A, Christie D (2005) Handbook of the birds of the world. Vol. 10: cuckoo-shrikes to thrushes. Lynx Edicions, Barcelona, 510-511. ISBN: 9788487334726

Dirzo R, Young HS, Galetti M, Ceballos G, Isaac NJ, Collen B (2014) Defaunation in the Anthropocene. Science 345(6195):401-406. https://doi.org/10.1126/science.1251817

Emer C, Galetti M, Pizo MA, Guimaraes PR Jr, Moraes S, Piratelli A, Jordano P (2018) Seed-dispersal interactions in fragmented landscapes-a metanetwork approach. Ecol Lett 21(4):484-493. https://doi.org/10.1111/ele.12909

Enssle F, Kabisch N (2020) Urban green spaces for the social interaction, health and well-being of older people - an integrated view of urban ecosystem services and socio-environmental justice. Environ Sci Pol 109:36-44. https://doi.org/10.1016/j.envsci.2020.04.008

Estevo CA, Nagy-Reis MB, Silva WR (2017) Urban parks can maintain minimal resilience for Neotropical bird communities. Urban For Urban Green 27:84-89. https://doi.org/10.1016/j.ufug.2017.06.013

Estrada A, Garber PA, Rylands AB, Roos C, Fernandez-Duque E, Di Fiore A, ..., Rovero F (2017) Impending extinction crisis of the world's primates: why primates matter. Sci Adv 3(1): e1600946. https://doi.org/10.1126/sciadv.1600946

Ewen JG, Walker L, Canessa S, Groombridge JJ (2015) Improving supplementary feeding in species conservation. Conserv Biol 29:341349. https://doi.org/10.1111/cobi.12410
Feeley KJ, Terborgh JW (2005) The effects of herbivore density on soil nutrients and tree growth in tropical forest fragments. Ecology 86(1):116-124. https://doi.org/10.1890/03-0657

Fent T (2008) Department of Economic and Social Affairs, population division, United Nations expert group meeting on social and economic implications of changing population age structures. Eur $\mathrm{J}$ Population 24(4):451-452. https://doi.org/10.1007/s10680-0089165-7

Foster MS (1977) Ecological and nutritional effects of food scarcity on a tropical frugivorous bird and its fruit source. Ecology 58(1):73-85. 3. https://doi.org/10.2307/1935109

Fox J, Weisberg S, Adler D, Bates D, Baud-Bovy G, Ellison S, ..., Heiberger R (2016) Package 'car'. Vienna: R Foundation for Statistical Computing. Available at: http://cran-r.project.org/web/ packages/car/car.pdf

Fragaszy DM, Visalberghi E, Fedigan LM (2004) The complete capuchin: the biology of the genus Cebus. Cambridge University Press, Cambridge ISBN: 0521661161

Fragoso JM (1997) Tapir-generated seed shadows: scale-dependent patchiness in the Amazon rain forest. J Ecol 519-529. https://doi. org $/ 10.2307 / 2960574$

Freitas CHD, Setz EZ, Araújo AR, Gobbi N (2008) Agricultural crops in the diet of bearded capuchin monkeys, Cebus libidinosus Spix (Primates: Cebidae), in forest fragments in Southeast Brazil. Revista Brasileira de Zoologia 25(1):32-39. https://doi.org/10. 1590/S0101-81752008000100006

Galbraith JA, Jones DN, Beggs JR, Parry K, Stanley MC (2017) Urban bird feeders dominated by a few species and individuals. Front Ecol Evol 5:81. https://doi.org/10.3389/fevo.2017.00081

Galetti M (1993) Diet of the scaly-headed parrot (Pionus maximiliani) in a semideciduous forest in southeastern Brazil. Biotropica, 419-425. https://doi.org/10.2307/2388865

Galetti M, Guevara R, Côrtes MC, Fadini R, Von Matter S, Leite AB, ..., Pires MM (2013) Functional extinction of birds drives rapid evolutionary changes in seed size. Science 340(6136): 1086-1090. https://doi.org/10.1126/science. 1233774

Gardner CJ, Bicknell JE, Baldwin-Cantello W, Struebig MJ, Davies ZG (2019) Quantifying the impacts of defaunation on natural forest regeneration in a global meta-analysis. Nat Commun 10(1):1-7. https://doi.org/10.1038/s41467-019-12539-1

Gasperin G, Pizo MA (2009) Frugivory and habitat use by thrushes (Turdus spp.) in a suburban area in South Brazil. Urban Ecosyst 12(4):425. https://doi.org/10.1007/s11252-009-0090-2

Gelmi-Candusso TA, Hämäläinen AM (2019) Seeds and the city: the interdependence of zoochory and ecosystem dynamics in urban environments. Front Ecol Evol 7:41. https://doi.org/10.3389/fevo. 2019.00041

Gómez-Baggethun E, Barton DN (2013) Classifying and valuing ecosystem services for urban planning. Ecol Econ 86:235-245. https://doi. org/10.1016/j.ecolecon.2012.08.019

Greenberg R, Mettke-Hofmann C (2001) Ecological aspects of neophobia and neophilia in birds. In: Current ornithology. Springer, Boston, pp 119-178. https://doi.org/10.1007/978-14615-1211-0 3

Guaratini MTG, Gomes EPC, Tamashiro JY, Rodrigues RR (2008) Composição florística da reserva municipal de Santa Genebra, Campinas, SP. Rev Bras Bot 31(2):323-337. https://doi.org/10. 1590/S0100-84042008000200015

Guix JC (2006) Complex plant-disperser-pest interactions in NW Amazonia: beetle larvae and companions travelling inside Attalea maripa palm nuts. Orsis: organismes i sistemes 21: 83-90. https:// www.raco.cat/index.php/Orsis/article/view/53172

Hale R, Swearer SE (2017) When good animals love bad restored habitats: how maladaptive habitat selection can constrain restoration. $\mathrm{J}$ Appl Ecol 54(5):1478-1486. https://doi.org/10.1111/1365-2664. 12829 
Hasui É, Metzger JP, Pimentel RG, Silveira LF, Bovo AA, Martensen AC et al (2018) ATLANTIC BIRDS: a data set of bird species from the Brazilian Atlantic forest. Ecology 99(2):497-497. https://doi.org/10. 1002/ecy.2119

Howe HF (1984) Implications of seed dispersal by animals for tropical reserve management. Biol Conserv 30(3):261-281. https://doi.org/ 10.1016/0006-3207(84)90087-9

Howe HF (1986) Seed dispersal by fruit-eating birds and mammals. Seed Dispers 123:189. https://doi.org/10.1016/B978-0-12-511900-9. 50009-7

Howe HF (2016) Making dispersal syndromes and networks useful in tropical conservation and restoration. Glob Ecol Conserv 6:152178. https://doi.org/10.1016/j.gecco.2016.03.002

Jones HP, Jones PC, Barbier EB, Blackburn RC, Rey Benayas JM, Holl KD, McCrackin M, Meli P, Montoya D, Mateos DM (2018) Restoration and repair of Earth's damaged ecosystems. Proc R Soc B Biol Sci 285(1873):20172577. https://doi.org/10.1098/rspb.2017. 2577

Jordano P, García C, Godoy JA, García-Castaño JL (2007) Differential contribution of frugivores to complex seed dispersal patterns. Proc Natl Acad Sci 104(9):3278-3282. https://doi.org/10.1073/pnas. 0606793104

Kissling DW, Böhning-Gaese K, Jetz W (2009) The global distribution of frugivory in birds. Glob Ecol Biogeogr 18(2):150-162. https://doi. org/10.1111/j.1466-8238.2008.00431.x

Kremer P, Hamstead Z, Haase D, McPhearson T, Frantzeskaki N, Andersson E et al (2016) Key insights for the future of urban ecosystem services research. Ecol Soc 21(2). https://doi.org/10.5751/ ES-08445-210229

Lam TTY, Jia N, Zhang YW, Shum MHH, Jiang JF, Zhu HC, ..., Li WJ (2020) Identifying SARS-CoV-2-related coronaviruses in Malayan pangolins. Nature 583, 282-285. https://doi.org/10.1038/s41586020-2169-0f

Lewis SL, Wheeler CE, Mitchard ET, Koch A (2019) Regenerate natural forests to store carbon. Nature 568(7750):25-28. https://doi.org/10. 1038/d41586-019-01026-8

Lopes HR, Abe AS (1999) Biologia reprodutiva e comportamento do teiu , Tupinambis merianae, em cativero (Rep- tilia, Teiidae). Pp. 259272 in T.G. Fang, O.L. Montenegro, and R.E. Bodmer, eds. Manejo y Conservacion de Fauna Silvestre en América Latina. Editorial Instituto e Ecología, La Paz. ISNN 591.042 C65

Ludwig G, Aguiar LM, Rocha VJ (2006) Comportamento de obtenção de Manihot esculenta Crantz (Euphorbiaceae), mandioca, por Cebus nigritus (Goldfuss)(Primates, Cebidae) como uma adaptação alimentar em períodos de escassez. Revista Brasileira de Zoologia 23(3):888-890. https://doi.org/10.1590/S010181752006000300039

Malhi Y, Gardner TA, Goldsmith GR, Silman MR, Zelazowski P (2014) Tropical forests in the Anthropocene. Annu Rev Environ Resour 39: 125-159. https://doi.org/10.1146/annurev-environ-030713-155141

Martin TE (1985) Resource selection by tropical frugivorous birds: integrating multiple interactions. Oecologia 66(4):563-573. https://doi. org/10.1007/BF00379351

Martin Schaefer H, Schaefer V, Vorobyev M (2007) Are fruit colors adapted to consumer vision and birds equally efficient in detecting colorful signals? Am Nat 169(S1):S159-S169. https://doi.org/10. $1086 / 510097$

Martinelli G, Valente ASM, Maurenza D, Kutschenko DC, Judice DM, Silva DS, ..., Santos-Filho LAF (2013) Avaliações de risco de extinção de espécies da flora brasileira. Livro vermelho da flora do Brasil, 60-103. ISBN 9788588742581

McAlpine C, Catterall CP, Nally RM, Lindenmayer D, Reid JL, Holl KD, ..., Seabrook L (2016) Integrating plant-and animal-based perspectives for more effective restoration of biodiversity. Front Ecol Environ, 14(1), 37-45. https://doi.org/10.1002/16-0108.1
McConkey KR, Brockelman WY (2011) Nonredundancy in the dispersal network of a generalist tropical forest tree. Ecology 92(7):14921502. https://doi.org/10.1890/10-1255.1

Melin AD, Nevo O, Shirasu M, Williamson RE, Garrett EC, Endo M, Sakurai K, Matsushita Y, Touhara K, Kawamura S (2019) Fruit scent and observer colour vision shape food-selection strategies in wild capuchin monkeys. Nat Commun 10(1):1-9. https://doi.org/10. 1038/s41467-019-10250-9

Melito M, Metzger JP, de Oliveira AA (2018) Landscape-level effects on aboveground biomass of tropical forests: a conceptual framework. Glob Chang Biol 24(2):597-607. https://doi.org/10.1111/gcb.13970

Mikich SB (1996) Análise quali-quantitativa do comportamento de Penelope superciliaris (Aves, Cracidae). Iheringia, Série Zoologia 81:87-95 ISSN: 0073-4721

Mikich SB, Liebsch D (2014a) Damage to forest plantations by tufted capuchins (Sapajus nigritus): too many monkeys or not enough fruits? For Ecol Manag 314:9-16. https://doi.org/10.1016/j.foreco. 2013.11.026

Mikich SB, Liebsch D (2014b) Assessment of food supplementation and surveillance as techniques to reduce damage caused by black capuchin monkeys Sapajus nigritus to forest plantations. Curr Zool 60(5):581-590. https://doi.org/10.1093/czoolo/60.5.581

Møller AP, Tryjanowski P, Díaz M, Kwieciński Z, Indykiewicz P, Mitrus C, Golawski A, Polakowski M (2015) Urban habitats and feeders both contribute to flight initiation distance reduction in birds. Behav Ecol 26(3):861-865. https://doi.org/10.1093/beheco/arv024

Morellato LPC (1991) Estudo da fenologia de árvores, arbustos e lianas de uma floresta semidecídua do sudeste do Brasil. Doctoral thesis, Instituto de Biologia. Universidade Estadual de Campinas. Campinas. Avaliable at: http://repositorio.unicamp.br/jspui/handle/ REPOSIP/315942

Morellato LPC, de Freitas Leitão Filho H (1995) Ecologia e preservação de uma floresta tropical urbana: Reserva de Santa Genebra. Editora da UNICAMP. ISBN:8526803638

Moreno-Mateos D, Alberdi A, Morriën E, van der Putten WH, Rodríguez-Uña A, Montoya D (2020) The long-term restoration of ecosystem complexity. Nat Ecol Evol 4:1-10. https://doi.org/10. 1038/s41559-020-1154-1

Morris DW (1989) Density-dependent habitat selection: testing the theory with fitness data. Evol Ecol 3(1):80-94. https://doi.org/10.1007/ BF02147934

Ness JH, Pfeffer M, Stark J, Guest A, Combs LJ, Nathan E (2016) In an arid urban matrix, fragment size predicts access to frugivory and rain necessary for plant population persistence. Ecosphere 7(6):e01284. https://doi.org/10.1002/ecs2.128

Oliveira-Filho AT, Fontes MAL (2000) Patterns of floristic differentiation among Atlantic forests in southeastern Brazil and the influence of climate 1. Biotropica 32(4b):793-810. https://doi.org/10.1111/j. 1744-7429.2000.tb00619.x

Ordano M, Blendinger PG, Lomáscolo SB, Chacoff NP, Sánchez MS, Nunez Montellano MG, Jiménez J, Ruggera RA, Valoy M (2017) The role of trait combination in the conspicuousness of fruit display among bird-dispersed plants. Funct Ecol 31(9):1718-1727. https:// doi.org/10.1111/1365-2435.12899

Ottoni I, de Oliveira FF, Young RJ (2009) Estimating the diet of urban birds: the problems of anthropogenic food and food digestibility. Appl Anim Behav Sci 117(1-2):42-46. https://doi.org/10.1016/j. applanim.2008.11.002

Paredes OSL, Norris D, Oliveira TGD, Michalski F (2017) Water availability not fruitfall modulates the dry season distribution of frugivorous terrestrial vertebrates in a lowland Amazon forest. PLoS One 12(3):e0174049. https://doi.org/10.1371/journal.pone.0174049

Péres Jr AK (2003) Sistemática e conservação do gênero Tupinambis (Squamata, Teiidae). Doctoral thesis, Universidade de Brasília, 192p (Not published) 
Pierotti R, Annett CA (1991) Diet choice in the herring gull: constraints imposed by reproductive and ecological factors. Ecology 72(1): 319-328. https://doi.org/10.2307/1938925

Pires MM, Galetti M (2020) Too big to fit. Front Ecol Environ 18(7): 400-400. https://doi.org/10.1002/fee.2248

Pizo MA (2004) Frugivory and habitat use by fruit-eating birds in a fragmented landscape of Southeast Brazil. Ornitologia Neotropical 15(1):117-126. Available at: http:/hdl.handle.net/11449/20241

Prasad S, Pittet A, Sukumar R (2010) Who really ate the fruit? A novel approach to camera trapping for quantifying frugivory by ruminants. Ecol Res 25(1):225-231. https://doi.org/10.1007/s11284-009-06501

Ramos-Robles M, Andresen E, Díaz-Castelazo C (2016) Temporal changes in the structure of a plant-frugivore network are influenced by bird migration and fruit availability. PeerJ 4:e2048. https://doi. org/10.7717/peerj.2048

Redford KH (1992) The empty forest. BioScience 42(6):412-422. https:// doi.org/10.2307/1311860

Ribeiro da Silva F, Montoya D, Furtado R, Memmott J, Pizo MA, Rodrigues RR (2015) The restoration of tropical seed dispersal networks. Restor Ecol 23(6):852-860. https://doi.org/10.1111/rec. 12244

Ribeiro MC, Metzger JP, Martensen AC, Ponzoni FJ, Hirota MM (2009) The Brazilian Atlantic Forest: how much is left, and how is the remaining forest distributed? Implications for conservation. Biol Conserv 142(6):1141-1153. https://doi.org/10.1016/j.biocon.2009. 02.021

Robb GN, McDonald RA, Chamberlain DE, Bearhop S (2008) Food for thought: supplementary feeding as a driver of ecological change in avian populations. Front Ecol Environ 6(9):476-484. https://doi. org/10.1890/060152

Rosenberg KV, Dokter AM, Blancher PJ, Sauer JR, Smith AC, Smith PA, Stanton JC, Panjabi A, Helft L, Parr M, Marra PP (2019) Decline of the north American avifauna. Science 366(6461):120 124. https://doi.org/10.1126/science.aaw1313

Rowles AD, O'Dowd DJ (2009) New mutualism for old: indirect disruption and direct facilitation of seed dispersal following argentine ant invasion. Oecologia 158(4):709-716. https://doi.org/10.1007/ s00442-008-1171-2

Seto KC, Güneralp B, Hutyra LR (2012) Global forecasts of urban expansion to 2030 and direct impacts on biodiversity and carbon pools. Proc Natl Acad Sci 109(40):16083-16088. https://doi.org/10.1073/ pnas. 1211658109

Silva WR, Zaniratto CP, Ferreira JO, Rigacci ED, Oliveira JF, Morandi ME, Killing JG, Nemes LG, Abreu LB (2020) Inducing seed dispersal by generalist frugivores: a new technique to overcome dispersal limitation in restoration. J Appl Ecol. https://doi.org/10.1111/ $1365-2664.13731$

Smith P, Derna R (2015) On the status of Dusky-legged guan Penelope obscura Temminck, 1815 (Aves: Cracidae) in Paraguay. Papéis Avulsos de Zoologia 55(14):211-216. https://doi.org/10.1590/ 0031-1049.2015.55.14

Steele MA, Bugdal M, Yuan A, Bartlow A, Buzalewski J, Lichti N, Swihart R (2011) Cache placement, pilfering, and a recovery advantage in a seed-dispersing rodent: could predation of scatter hoarders contribute to seedling establishment? Acta Oecol 37(6):554-560. https://doi.org/10.1016/j.actao.2011.05.002

Tabarelli M, Gascon C (2005) Lessons from fragmentation research: improving management and policy guidelines for biodiversity conservation. Conserv Biol 19(3):734-739. https://doi.org/10.1111/j. 1523-1739.2005.00698.x

Tabarelli M, Peres CA (2002) Abiotic and vertebrate seed dispersal in the Brazilian Atlantic forest: implications for forest regeneration. Biol Conserv 106(2):165-176. https://doi.org/10.1016/S0006-3207(01) 00243-9
Terborgh J (2013) Using Janzen-Connell to predict the consequences of defaunation and other disturbances of tropical forests. Biol Conserv 163:7-12. https://doi.org/10.1016/j.biocon.2013.01.015

Terborgh J, Nuñez-Iturri G, Pitman NC, Valverde FHC, Alvarez P, Swamy V, Pringle EG, Paine CT (2008) Tree recruitment in an empty forest. Ecology 89(6):1757-1768. https://doi.org/10.1890/ 07-0479.1

Timilsina N, Escobedo FJ, Staudhammer CL, Brandeis T (2014) Analyzing the causal factors of carbon stores in a subtropical urban forest. Ecol Complex 20:23-32. https://doi.org/10.1016/j.ecocom. 2014.07.001

Traveset A (1998) Effect of seed passage through vertebrate frugivores' guts on germination: a review. Perspect Plant Ecol Evol System 1(2):151-190. https://doi.org/10.1078/1433-8319-00057

Traveset A, Robertson AW, Rodríguez-Pérez J (2007) A review on the role of endozoochory in seed germination. Seed dispersal: theory and its application in a changing world, 78-103. In: Dennis AJ, Schupp EW, Green RJ, Westcott DA (eds) Seed dispersal: theory and its application in a changing world. $\mathrm{CAB}$ International, Wallingford, pp 78-103 ISBN: 9781845931650

Tsunamoto Y, Naoe S, Masaki T, Isagi Y (2020) Different contributions of birds and mammals to seed dispersal of a fleshy-fruited tree. Basic Appl Ecol 43:66-75. https://doi.org/10.1016/j.baae.2019.07.005

Tylianakis JM, Laliberté E, Nielsen A, Bascompte J (2010) Conservation of species interaction networks. Biol Conserv 143(10):2270-2279. https://doi.org/10.1016/j.biocon.2009.12.004

United Nations (2018) 2018 Revision of world urbanization prospects. Retrieved from https://population.un.org/wup/

Valenta K, Nevo O, Martel C, Chapman CA (2017) Plant attractants: integrating insights from pollination and seed dispersal ecology. Evol Ecol 31(2):249-267. https://doi.org/10.1007/s10682-016-9870-3

Valido A, Olesen JM (2007) The importance of lizards as frugivores and seed dispersers. Seed dispersal: theory and its application in a changing world. Wallingford, UK: CAB International, 124-147. In: Dennis AJ, Schupp EW, Green RJ, Westcott DA (eds) Seed dispersal: theory and its application in a changing world. CAB International, Wallingford, pp 78-103 ISBN: 9781845931650

Valiente-Banuet A, Aizen MA, Alcántara JM, Arroyo J, Cocucci A, Galetti M, ..., Medel R (2015) Beyond species loss: the extinction of ecological interactions in a changing world. Funct Ecol 29(3): 299-307. https://doi.org/10.1111/1365-2435.12356

Van der Pijl L (1982) Principles of dispersal. SpringerVerlag, Berlin. https://doi.org/10.1007/978-3-642-87925-8

Vilanova R, de Sousa J, Grelle CEV, Marroig G, Cerqueira R (2005) Limites climáticos e vegetacionais das distribuições de Cebus nigritus e Cebus robustus (Cebinae, Platyrrhini). Neotropic Primates 13(1):14-19. https://doi.org/10.1896/1413-4705.13.1.14

Vitousek PM, D'antonio CM, Loope LL, Rejmanek M, \& Westbrooks R (1997) Introduced species: a significant component of humancaused global change. New Zealand Journal of Ecology, 1-16.

Wheelwright NT (1985) Fruit-size, gape width, and the diets of fruiteating birds. Ecology 66(3):808-818. https://doi.org/10.2307/ 1940542

Wickham H (2016) ggplot2: elegant graphics for data analysis. Springer, Berlin ISBN: 9783319242774

Willis EO, Oniki Y (2002) Birds of a Central São Paulo woodlot: 1. Censuses 1982-2000. Braz J Biol 62(2):197-210. https://doi.org/ 10.1590/S1519-69842002000200003

Wintle BA, Kujala H, Whitehead A, Cameron A, Veloz S, Kukkala A, Moilanen A, Gordon A, Lentini PE, Cadenhead NCR, Bekessy SA (2019) Global synthesis of conservation studies reveals the importance of small habitat patches for biodiversity. Proc Natl Acad Sci 116(3):909-914. https://doi.org/10.1073/pnas.1813051115

Wright SJ, Duber HC (2001) Poachers and forest fragmentation alter seed dispersal, seed survival, and seedling recruitment in the palm Attalea butyraceae, with implications for tropical tree diversity 1 . Biotropica 
33(4):583-595. https://doi.org/10.1111/j.1744-7429.2001.tb00217. $\mathrm{x}$

Zaca W, Silva WR, Pedroni F (2006) Diet of the rusty-margined guan (Penelope superciliaris) in an altitudinal forest fragment of southeastern Brazil. Ornitol Neotropic 17:373-382

Zhou HP, Chen J (2010) Spatial genetic structure in an understorey dioecious fig species: the roles of seed rain, seed and pollen-mediated gene flow, and local selection. J Ecol 98(5):1168-1177. https://doi. org $/ 10.1111 / \mathrm{j} .1365-2745.2010 .01683 . \mathrm{x}$

Zhou P, Yang XL, Wang XG, Hu B, Zhang L, Zhang W, ..., Chen HD (2020) A pneumonia outbreak associated with a new coronavirus of probable bat origin. Nature 1-4. https://doi.org/10.1038/s41586$020-2012-7$ 